\title{
Tests of a Prototype for Assessing the Field Homogeneity of the Iseult/Inumac 11.7T Whole Body MRI Magnet
}

\author{
L. Quettier, G. Aubert, P. Bredy, A. Chance, F. Nunio, T. Schild, V. Stepanov, P.Vedrine, \\ A. Donati, F. Beaudet.
}

\begin{abstract}
A neuroscience research center with very high field MRI equipments has been opened in November 2006 by the CEA life science division. One of the imaging systems will require a 11.75 $T$ magnet with a $900 \mathrm{~mm}$ warm bore, the so-call Iseult/Inumac magnet. Regarding the large aperture and field strength, this magnet is a challenge as compared to the largest MRI systems ever built, and is then developed within an ambitious $R \& D$ program.

With the objective of demonstrating the possibility of achieving field homogeneity better than $1 \mathrm{ppm}$ using double pancake windings, a 24 double pancakes model coil, working at $1.5 \mathrm{~T}$ has been designed.

This model magnet has been manufactured by Alstom MSA and tested at CEA. It has been measured with a very high precision, in order to fully characterize the field homogeneity, and then to investigate and discriminate the parameters that influence the field map.

This magnet has reached the bare magnet field homogeneity specification expected for Iseult and thus successfully demonstrated the feasibility of building a homogenous magnet with the double pancake winding technique.
\end{abstract}

Index Terms-MRI, Double Pancake, High Field, Magnetic Measurements

\section{INTRODUCTION}

$\mathrm{T}_{\mathrm{very}}^{\mathrm{H}}$ HE life science division of CEA has launched in 2006 a very ambitious very high field MRI research project, Iseult/Inumac in collaboration with industrial partners, Alstom MSA and Siemens Medical Systems. A $500 \mathrm{MHz}$ whole body magnet is a part of this project [1]. During the preliminary design phase [2], an innovative winding method for MRI using double pancake (DP) with a controlled geometry has been developed [3].

A MRI magnet is designed in order to have a field spatial homogeneity according to imaging requirements, in our case the field variation has to be lower than $0.5 \mathrm{ppm}$ peak-to-peak in a $22 \mathrm{~cm}$ diameter sphere. Due to the innovative winding, it is too risky to rely only on computation to specify shimming

Manuscript received 26 October 2009.

L. Quettier was with the CEA, Irfu, SACM, Centre de Saclay, F-91191 Gif sur Yvette, France. He is now with Jefferson Lab, 12000 Jefferson Ave, Newport News, VA 23606, USA. (e-mail:quettier@jab.org).

G. Aubert, P. Bredy, A. Chancé, F. Nunio, Th. Schild, V. Stepanov, P.Vedrine and A. Donati are with the CEA, Irfu, SACM, Centre de Saclay, F91191 Gif sur Yvette, France (e-mail: thierry.schild@cea.fr).

F. Beaudet is with Alstom-MSA, 3bis avenue des Trois Chênes, 90018

Belfort, France (e-mail: francois.beaudet@power.alstom.com). coils. A reduced scale prototype is under construction in order to measure the achievable manufacturing tolerances and to check the agreement with computation.

The prototype design and drawings were performed by CEA whereas its manufacturing, including tooling design and manufacturing has been achieved by Alstom-MSA. Tests and magnetic measurements have been performed at CEA. The goal of this prototype magnet was on the one hand to demonstrate the winding design efficiently for MRI, and on the other hand to give an experimental basis for the cryoshim specification.

\section{PRototype DeSIGN}

\section{A. Magnet Design}

The central field of the magnet and the warm bore are respectively $1.5 \mathrm{~T}$ and $300 \mathrm{~mm}$ in order to fit existing accurate field mapping devices. The winding was made using a rectangular monolithic NbTi composite.

The formulation given by (1) has been chosen for spherical harmonic expansion (SHE) of the central field.

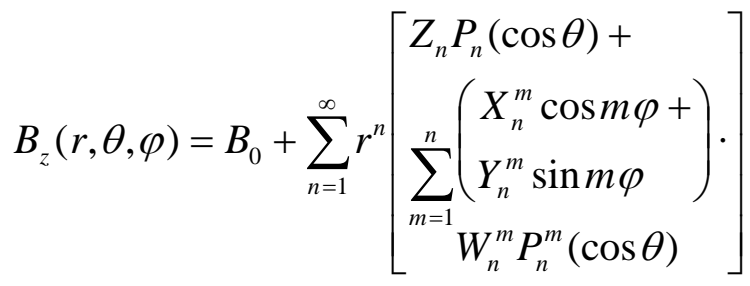

$W_{n}{ }^{m}$ is given by (2) and it is a weight factor used in order to have comparable values for $X_{n}^{m}, Y_{n}^{m}, Z_{n}$ coefficients.

$$
W_{n}^{m}=\frac{(n-m-1) ! !}{(n-m+1) ! !}
$$

The magnet was designed in order to cancel 10 firsts orders from the SHE using 24 DP thanks to an optimization of the axial distance between each DP. With the imposed DP geometry, the symmetry of the DP positions with the median magnet plan is enough to ensure that the off-axis term of the SHE are negligible [3]. Besides, a special care has also been taken in the jointing between DP. A loop has been designed for each junction with an alternate current path sign in order 
not to induce field error. All this was made in order to reach a MRI field quality [4].

Fig. 1 shows a picture of the manufactured magnet design.

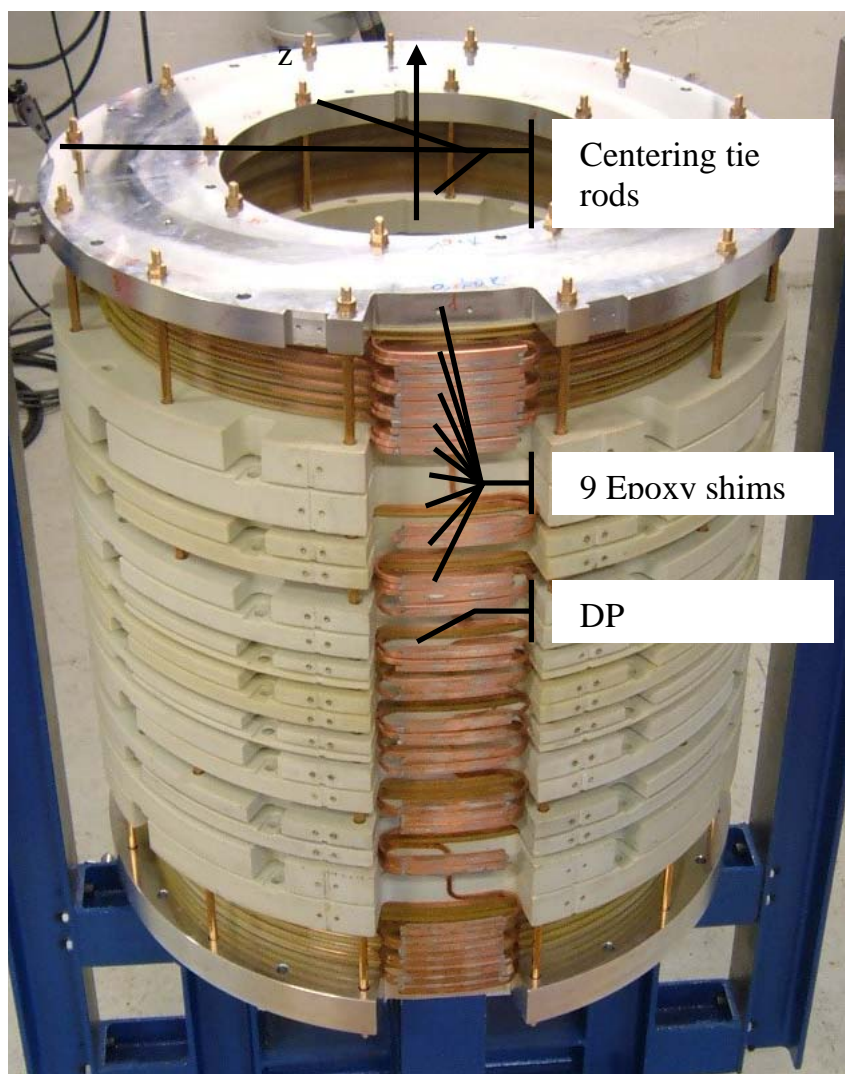

Fig. 1 Picture of the prototype magnet

\section{B. Manufacturing tolerances}

Tightened tolerances have been imposed during the manufacturing (Table I).

As the winding geometry is very important for the field quality, an accurate online control of the radial position of the conductor during pancake winding has been performed [6] and the effects of the real DP size have then been calculated.

TABLE I MAGNET MANUFACTURING TOLERANCES

\begin{tabular}{lcrr}
\hline \hline \multicolumn{1}{c}{ Quantity } & Unit & $\begin{array}{r}\text { Tolerance } \\
\text { expected }\end{array}$ & $\begin{array}{r}\text { Tolerance } \\
\text { measured }\end{array}$ \\
\hline Inner DP radius & $\mathrm{mm}$ & $+/-0.05$ & $+/-0.06$ \\
Outer DP radius & $\mathrm{mm}$ & $+/-0.85$ & $-0.85 /+0.25$ \\
Average DP thickness & $\mathrm{mm}$ & $+/-0.1$ & $+0.08 /-0.07^{*}$ \\
DP thickness dispersion & $\mathrm{mm}$ & & $+0.09 /+0.29^{* *}$ \\
DP Belleville spring & $\mathrm{mm}$ & $+/-0.05$ & $-0.06 /+0.33$ \\
Inter DP insul. Thickness & $\mathrm{mm}$ & $+/-0.3$ & $+/-0.06$ \\
DP centre relatively to & $\mathrm{mm}$ & & $+/-0.3$ \\
magnet center & & & \\
$\begin{array}{l}\text { DP tilt relatively to magnet } \\
\text { median plan }\end{array}$ & $\mathrm{mrad}$ & & \\
\hline \hline
\end{tabular}

* Variation of the average DP thickness

** Before DP assembling

Taking into account values given in Table I, a statistical estimation of the bare magnet field homogeneity has been done assuming uniform error distribution. Results are given in Table II and they are given in ppm of the nominal field, $1.5 \mathrm{~T}$, and using the formulation given by (1) for a reference radius of $0.15 \mathrm{~m}$.

\begin{tabular}{|c|c|}
\hline Term of SHE & $\begin{array}{c}\text { Estimated } \\
\text { values [ppm] }\end{array}$ \\
\hline$Z_{1}$ & 450 \\
\hline$Z_{2}$ & 340 \\
\hline$Z_{3}$ & 240 \\
\hline$Z_{4}$ & 150 \\
\hline$X_{11} / Y_{11}$ & 180 \\
\hline$X_{21} / Y_{21}$ & 180 \\
\hline
\end{tabular}

Finally, pre-load and thermal contractions have been taken into account and lead to the results of Table III for an average thermal shrinkage of $0.3 \mathrm{~mm} / \mathrm{m}$. As expected, the estimated magnet homogeneity after manufacturing is better than the estimated bare magnet homogeneity based only on tolerances.

TABLE III ESTIMATED ON-AXIS TERMS OF SHE

\begin{tabular}{lrlr}
\hline \hline Term & Values $[\mathrm{ppm}]$ & Term & Values [ppm] \\
\hline$Z_{1}$ & 36.1 & $Z_{8}$ & -2.2 \\
$Z_{2}$ & -7.1 & $Z_{9}$ & 2.8 \\
$Z_{3}$ & -11.1 & $Z_{10}$ & -6.6 \\
$Z_{4}$ & -9.1 & $Z_{11}$ & 2.6 \\
$Z_{5}$ & 4.2 & $Z_{12}$ & -86.2 \\
$Z_{6}$ & -6.4 & $Z_{13}$ & -3.2 \\
$Z_{7}$ & -3.9 & $Z_{14}$ & 70.2 \\
\hline \hline
\end{tabular}

The magnet was designed in order to cancel up to 10 orders from the SHE: terms lower than 12 orders are due to manufacturing errors, terms of even order equal to or higher than 12 are due to magnet design.

\section{MAGNETIC MEASUREMENTS}

\section{A. Experimental setup}

The magnet is powered in driven mode using an existing power supply stabilized at $2 \mathrm{ppm} / \mathrm{h}$. The magnet is cooled down in a helium bath at atmospheric pressure and at $4.2 \mathrm{~K}$.

\section{B. Magnetic measurements method and accuracy}

The field homogeneity has been measured using a Metrolab field camera. This camera is made of $18 \mathrm{NMR}$ probes located on a half circle of $300 \mathrm{~mm}$ in diameter. As represented on Fig. 2, the half moon probe array is placed on an aluminium probe holder to be rotated around the vertical axis with 36 angular positions per turn.

Magnetic field acquisition is performed at each angular position and a complete mapping is done without any displacement of the probe holder. The vertical component of the magnetic field is thus obtained for 648 points of a sphere and a mathematical decomposition allows then calculating onaxis terms of the SHE up to the order 17.

Besides, the probe holder was able to move in any radial direction using a special mechanical device. This was done in order to fit the rotation axis with the central axis of the magnet as the real location of the magnetic axis with respect to the probe holder axis was not known enough precisely to get the required measurement accuracy. The field camera location was determined by shifting horizontally the rotation axis in 
order to minimize $X_{11-1}$ term of SHE. Then, the camera vertical position was adjusted in order to minimize $Z_{11}$ term of SHE. Moreover, the measurement precision has been evaluated to be under $0.1 \mathrm{ppm}$ using several reproducibility tests.

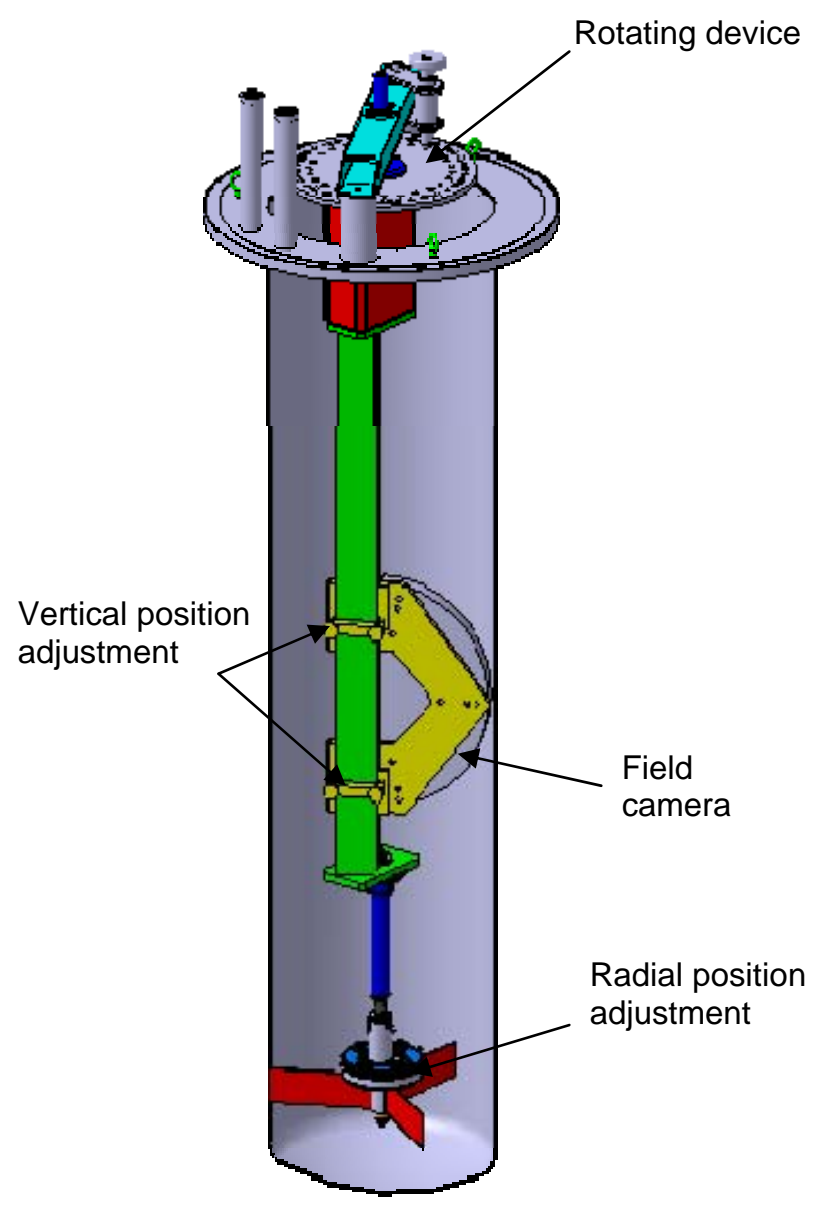

Fig. 2 Sketch of the probe holder

\section{Results of magnetic measurements}

The magnet has been tested several times, including a complete thermal cycling and a warm up from cryogenic to ambient temperature between two successive runs. Magnetic measurements results obtained for the four campaigns are given in table IV and $\mathrm{V}$, for a radius of $0.15 \mathrm{~m}$.

TABLE IV MEASURED ON-AXIS TERMS OF SHE (IN PPM)

\begin{tabular}{lrrrr}
\hline \hline $\begin{array}{c}\text { On-axis } \\
\text { Term }\end{array}$ & $\begin{array}{r}\text { Campaign } \\
1\end{array}$ & $\begin{array}{c}\text { Campaign } \\
2\end{array}$ & $\begin{array}{c}\text { Campaign } \\
3\end{array}$ & \multicolumn{1}{c}{ Campaign } \\
\hline$Z_{1}$ & 28.5 & 29.9 & 26.1 & 26.7 \\
$Z_{2}$ & -108.5 & -108.6 & -103.4 & -100.3 \\
$Z_{3}$ & -12.7 & -11.5 & -12.0 & -13.7 \\
$Z_{4}$ & -10.5 & -10.2 & -8.3 & -8.6 \\
$Z_{5}$ & 1.4 & 1.0 & 1.3 & 1.7 \\
$Z_{6}$ & -4.0 & -3.6 & -5.0 & -4.4 \\
$Z_{7}$ & -2.2 & -2.1 & -2.5 & -2.5 \\
$Z_{8}$ & -1.5 & -1.3 & -0.6 & -0.7 \\
$Z_{9}$ & 1.4 & 1.2 & 1.5 & 1.1 \\
$Z_{10}$ & -5.4 & -2.7 & -7.1 & -7.2 \\
$Z_{11}$ & 2.3 & 1.8 & -4.8 & -8.3 \\
$Z_{12}$ & -85.3 & -89.4 & -85.6 & -85.4 \\
$Z_{13}$ & -2.9 & -2.4 & 3.8 & 7.3 \\
$Z_{14}$ & 68.8 & 71.2 & 69.1 & 69.0 \\
\hline
\end{tabular}

TABLE V MEASURED OFF-AXIS TERMS OF SHE (IN PPM)

\begin{tabular}{|c|c|c|c|c|}
\hline $\begin{array}{c}\text { Off-axis } \\
\text { Term }\end{array}$ & $\begin{array}{c}\text { Campaign } \\
1\end{array}$ & $\begin{array}{c}\text { Campaign } \\
2\end{array}$ & $\begin{array}{c}\text { Campaign } \\
3\end{array}$ & $\begin{array}{c}\text { Campaign } \\
4\end{array}$ \\
\hline$X_{11}$ & 16.4 & 2.0 & -21.1 & -19.3 \\
\hline$Y_{11}$ & -30.2 & -55.6 & -102.4 & -109.7 \\
\hline$X_{21}$ & -114.8 & -150.9 & -194.8 & -201.4 \\
\hline$Y_{21}$ & -27.8 & -23.8 & -18.2 & -19.7 \\
\hline$X_{22}$ & -24.7 & -26.2 & -24.5 & -24.8 \\
\hline$Y_{22}$ & -13.1 & -14.6 & -12.3 & -11.9 \\
\hline$X_{31}$ & -14.5 & -9.4 & -3.5 & -1.5 \\
\hline$Y_{31}$ & 14.4 & 16.8 & 32.7 & 34.4 \\
\hline$X_{32}$ & 12.0 & 11.3 & 11.1 & 11.6 \\
\hline$Y_{32}$ & 3.1 & 4.2 & 1.4 & 1.5 \\
\hline$X_{33}$ & -2.1 & -1.3 & -1.7 & -1.7 \\
\hline$Y_{33}$ & -0.5 & -0.1 & -1.1 & -0.6 \\
\hline$X_{41}$ & 40.6 & 52.8 & 65.0 & 68.4 \\
\hline$Y_{41}$ & -2.4 & -6.5 & -13.7 & -13.9 \\
\hline$X_{42}$ & 10.3 & 10.2 & 9.6 & 10.0 \\
\hline$Y_{42}$ & 9.3 & 9.2 & 8.7 & 8.4 \\
\hline$X_{43}$ & -0.5 & -0.2 & -1.0 & -0.9 \\
\hline$Y_{43}$ & -3.0 & -3.2 & -2.8 & -2.8 \\
\hline$X_{44}$ & 0.2 & 0.1 & 0.2 & 0.1 \\
\hline$Y_{44}$ & -0.4 & -0.5 & -0.6 & -0.6 \\
\hline
\end{tabular}

\section{RESULTS ANALYSIS}

\section{A. Comparison between calculated and measured on-axis terms of SHE}

The four campaigns lead to the same order of magnitude for all the on-axis terms. Table IV and IV show a good agreement for on-axis terms of SHE, except for $Z_{2}$. This term, as all the even on-axis terms of SHE, is very sensitive to axial thermal contraction from 300 to $4.2 \mathrm{~K}$.

As the magnet is a non homogenous media, made of copper, insulation, and epoxy shims, the real value is difficult to predict. The high sensitivity of axial thermal contraction of $Z_{2}$ can be shown on Table VI.

\begin{tabular}{lr} 
TABLE VI & AXIAL THERMAL CONTRACTION SENSITIVITY \\
\hline \hline $\begin{array}{l}\text { Thermal contraction coefficient } \\
\text { from } 300 \text { to } 4.2 \mathrm{~K}\end{array}$ & $Z_{2}$ in ppm \\
\hline 0.003 & -7.1 \\
0.0035 & -71.5 \\
0.004 & -107.7 \\
0.0045 & -125.9 \\
\hline
\end{tabular}

\section{B. Comparison between calculated and measured off-axis terms of SHE}

Table V show an evolution of X21, X31 and X41 terms during the four campaigns. Besides, Tables III and V show some differences for off-axis terms of SHE. First order off-axis terms are higher than expected, which can be explained by a DP shift. As explained in [5], this error can be explained by in-plane shift of DP in the range of $0.1 \mathrm{~mm} . X_{21}$ is rather high even if it is still within estimation [6].

As no geometrical control of the in-plane position of DP has been done after pre-compression, one has finally decided to perform a geometrical survey of the magnet at room temperature after the campaign 4 . As represented on figure 4, measured centres are located on a helix with a path of the same order than the coil height. Radial shifts measured on the 24 DP centres are within the expected tolerance of $0.3 \mathrm{~mm}$ given in Table I. 


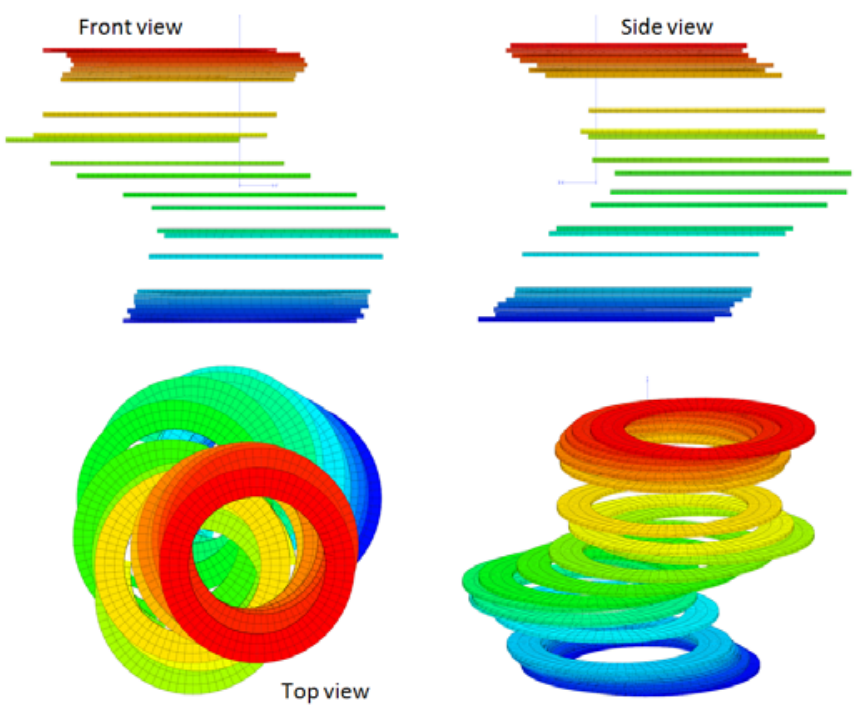

Fig. 3 View of the coil deformation ( scaling factor of 1000)

A new magnetic calculation using the measured position of the 24Ps centres and results for off-axis term are given in Table VII for a radius of $0.15 \mathrm{~m}$ (on-axis terms keep the same values as they are not affected by a purely small radial shift).

TABLE VII OFF-AXIS TERMS OF SHE WITH THE NEW DP LOCATIONS

\begin{tabular}{lrlr}
\hline \hline Term & Values $[\mathrm{ppm}]$ & Term & Values [ppm] \\
\hline$X_{11}$ & 3.4 & $X_{32}$ & 0 \\
$Y_{11}$ & -188.6 & $Y_{32}$ & 0.2 \\
$X_{21}$ & -188.5 & $X_{33}$ & 0 \\
$Y_{21}$ & -26.9 & $Y_{33}$ & 0 \\
$X_{22}$ & -0.1 & $X_{41}$ & 57.4 \\
$Y_{22}$ & 0 & $Y_{41}$ & -5.1 \\
$X_{31}$ & -12.8 & $X_{42}$ & 0.1 \\
$Y_{31}$ & 65.2 & $Y_{42}$ & 0 \\
\hline
\end{tabular}

This shift cannot come from DP manufacturing as the DP centre regarding centring holes is well within the error. The deformation has been initially generated during the DPs assembling, and it seems it has still evolved during the different thermal cycles applied on the magnet and/or during axial-load. As there is no significant evolution between campaign 3 and campaign 4, one can considerer a limit has been reached, but the manufacturing process is still under investigation in order to understand more precisely the origin of this helix shape. Second order off-axis terms are higher than expected from the tolerance analysis. No geometrical control of the in-plane position of DP has been done after precompression. This error should come from an elliptical deformation of less than $0.1 \mathrm{~mm}$ on central DP after assembling, otherwise such a deformation would have been measured with online control and 3D control.

\section{CONCLUSIONS}

A model magnet using the innovative winding geometry developed within the Iseult R\&D has been manufactured and successfully tested. It has been measured with a very high precision, in order to fully characterize the field homogeneity, and then to investigate and discriminate the parameters that influence the field map. This prototype magnet is much more sensitive to winding defaults than the $11.7 \mathrm{~T}$ Iseult magnet because of the scaling factor between the two magnets. The Iseult magnet inner radius is namely $0.5 \mathrm{~m}$, versus only $0.24 \mathrm{~m}$ for the prototype magnet. SHE obtained for campaign 4 at a $0.15 \mathrm{~m}$ radius and SHE scaled for the Iseult magnet at a 0.11 $\mathrm{m}$ radius are given in Table VIII.

\begin{tabular}{|c|c|c|c|c|c|}
\hline Term & $\begin{array}{c}\text { Campaign } \\
4\end{array}$ & $\begin{array}{l}\text { Scaled } \\
\text { Results }\end{array}$ & Term & $\begin{array}{c}\text { Campaign } \\
4\end{array}$ & $\begin{array}{l}\text { Scaled } \\
\text { Results }\end{array}$ \\
\hline$\overline{Z_{1}}$ & 26.7 & 9.4 & $Y_{32}$ & 1.5 & 0.3 \\
\hline$X_{11}$ & -19.3 & -6.8 & $X_{33}$ & -1.7 & -0.3 \\
\hline$Y_{11}$ & -109.7 & -38.6 & $Y_{33}$ & -0.6 & -0.1 \\
\hline$Z_{2}$ & -100.3 & -25.9 & $Z_{4}$ & -8.6 & -1.2 \\
\hline$X_{21}$ & -201.4 & -52.0 & $X_{41}$ & 68.4 & 9.5 \\
\hline$Y_{21}$ & -19.7 & -5.1 & $Y_{41}$ & -13.9 & -1.9 \\
\hline$X_{22}$ & -24.8 & -6.4 & $X_{42}$ & 10.0 & 1.4 \\
\hline$Y_{22}$ & -11.9 & -3.1 & $Y_{42}$ & 8.4 & 1.2 \\
\hline$Z_{3}$ & -13.7 & -2.6 & $X_{43}$ & -0.9 & -0.1 \\
\hline$X_{31}$ & -1.5 & -0.3 & $Y_{43}$ & -2.8 & -0.4 \\
\hline$Y_{31}$ & 34.4 & 6.5 & $X_{44}$ & 0.1 & 0 \\
\hline$X_{32}$ & 11.6 & 2.2 & $Y_{44}$ & -0.6 & -0.1 \\
\hline
\end{tabular}

Finally, due to manufacturing tolerances, bare magnet homogeneity is never as good as expected according to its theoretical perfect design. So, it is necessary to foresee superconducting shimming coils [4] within the magnet helium vessel or some pieces of iron within the warm bore to correct the field. As iron shimming is not efficient enough at very high field, superconducting shimming coils have to be specified for Iseult. As extrapolated values of table VI are clearly compatible with usual shimming technology, the prototype magnet demonstrates that the proposed winding geometry is readily applicable for MRI magnet. In addition, the very good agreement between field calculations based on warm geometrical checks and field measurements shows that these check will be a very efficient tool to control manufacturing quality at key phases.

\section{ACKNOWLEDGMENT}

The authors want to thank technicians from CEA and Alstom-MSA having participated to the prototype winding for the quality of their work.

\section{REFERENCES}

[1] P. Vedrine et al., "The Whole Body 11.7 T MRI Magnet for Iseult/INUMAC Project," IEEE Transactions on Applied Superconductivity, vol. 18, pp. 868-873, 2008.

[2] T. Schild et al, "The Iseult/Inumac Whole Body 11.7 T MRI Magnet Design," IEEE Transactions on Applied Superconductivity, vol. 18, pp. 904-907, 2008.

[3] G. Aubert, "Method and Device for Generating a Homogenous Magnetic Field in an Area of Interest, Especially for NMR Imaging," Patent WO2007/077383, Jul. 12, 2007.

[4] D.I. Hoult and Françoise Roméo, "Magnet field profiling: Analysis and correcting coil design," Magnetic Resonance in Medicine, vol. 1, pp. 4465, 1984.

[5] G. Aubert and A. Chancé, "Relations between the winding errors of the double pancakes and the development in Spherical Harmonics of the field”, to be published in IEEE Trans. On. Magn.

[6] Th. Schild et al, A Prototype for Assessing the Field Homogeneity of the Iseult MRI Magnet, IEEE Transactions on Applied Superconductivity, vol. 19, June 2009. 